\title{
To Be or not To Be Involved: A Questionnaire-Experimental View on Harsanyi's Utilitarian Ethics
}

\author{
Yoram Amiel*, Frank A. Cowell ${ }^{\dagger}$, Wulf Gaertner ${ }^{\ddagger}$
}

DARP 85

February 2006
The Toyota Centre

Suntory and Toyota International Centres for Economics and Related Disciplines

London School of Economics

Houghton Street

London WC2A $2 \mathrm{~A}$

(+44 020) 79556674

\footnotetext{
${ }^{*}$ Ruppin Academic Center, Israel

${ }^{\dagger}$ London School of Economics

\$ Universität Osnabrück
} 


\begin{abstract}
According to standard theory founded on Harsanyi $(1953,1955)$ a social welfare function can be appropriately based on the individual's approach to choice under uncertainty. We investigate whether people really do rank distributions according to the same principles irrespective of whether the comparison involves money payoffs in a risky situation or the distribution of income among persons. We use a questionnaire experiment to focus on the two different interpretations of the Harsanyi approach. There are important, systematic differences that transcend the cultural background of respondents.
\end{abstract}

Keywords: $\quad$ Impartial observer theorem, utilitarianism, welfare.

JEL Classification: C13, D63.

We are grateful to Sanghamitra Bandyopadhyay for research assistance. 


\section{Distributional Analysis Research Programme}

The Distributional Analysis Research Programme was established in 1993 with funding from the Economic and Social Research Council. It is located within the Suntory and Toyota International Centres for Economics and Related Disciplines (STICERD) at the London School of Economics and Political Science. The programme is directed by Frank Cowell. The Discussion Paper series is available free of charge. To subscribe to the DARP paper series, or for further information on the work of the Programme, please contact our Research Secretary, Leila Alberici on:

Telephone: UK+20 79556674

Fax: $\quad$ UK+2079556951

Email: $\quad$ 1.alberici@1se.ac.uk

Web site: $\quad$ http://sticerd.lse.ac.uk/DARP

(C) Authors: Yoram Amiel, Frank A. Cowell and Wulf Gaertner

All rights reserved. Short sections of text, not to exceed two paragraphs, may be quoted without explicit permission provided that full credit, including $(\mathrm{C}$ notice, is given to the source. 


\section{Introduction}

How should the benefits and burdens of a society be divided up among its members? This is a difficult question indeed but many people will agree that this division should be based on impartiality. Stakes or vested interests should not play a role. How can impartiality be achieved? In his "The Theory of Moral Sentiments" (1759, [1976]) Adam Smith developed the concept of an impartial spectator. On the first page of this work, Smith wrote: "As we have no immediate experience of what other men feel, we can form no idea of the manner in which they are affected, but by conceiving what we ourselves should feel in the like situation". A few lines below, Smith was a bit more explicit: "By the imagination we place ourselves in his (i.e. our brother's) situation, we conceive ourselves enduring all the same torments, we enter as it were into his body, and become in some measure the same person with him, and hence form some idea of his sensations, and even feel something which, though weaker in degree, is not altogether unlike them". Smith argued that a spectator can only imagine from some distance the sentiments that arise in the persons he is about to evaluate. In order to make his judgments properly, the spectator should be well informed and take up an impartial attitude.

Almost exactly two centuries later, Vickrey (1945) and Harsanyi (1953, 1955) came up with the suggestion that vectors of income distribution or, more generally, social states should be evaluated from the viewpoint of an impartial observer, who knows the income values but is completely ignorant of his own position and the positions of the other members of society. Again roughly twenty years later, Rawls (1971) put forward a contractarian view. He suggested two principles of justice for the basic structure of society that free and rational individuals would agree upon under a veil of ignorance where no one knows his place in society nor his class position or social status, nor his fortune in the distribution of natural assets and abilities.

In this paper, we wish to focus entirely on Harsanyi's two models of utilitarian ethics based on the Bayesian theory of rational behaviour and the concept of a cardinal von Neumann-Morgenstern utility function. Some have argued that the two models are not really distinct and that the distributional ethics from each of them are effectively identical. This paper takes issue with that position by focusing on the role of involvement in the distributional judgment. It reports the result of a series of simple questionnaire experiments that allows one to examine differences in distributional rankings according to each of the two types of Harsanyi model. In a companion paper (Amiel et al., 2006), we are looking at impersonal risk and risk with personal involvement outside the utilitarian set-up. We only know of one other study that is somewhat related to our own. Herne and Suojanen (2004) have looked at the role of the veil of ignorance within Rawls's set-up. Their experimental study investigates whether groups of individuals in two simulated original positions, one with and the other without a veil of ignorance, make different choices.

Section 2 provides the theoretical background for Harsanyi's two models and section 3 sets out the nature of the questionnaire experiment. Section 4 presents an 
overview of the results and section 5 offers an interpretation.

\section{Harsanyi's Two Models}

The first of Harsanyi's two models is commonly referred to as "Harsanyi's aggregation theorem" (Weymark 1991). It says that if the individual preferences and the social preference relation satisfy the expected utility axioms and if $V_{i}$ and $V$ are the von Neumann-Morgenstern utility representations of these individual relations and the social preference relation respectively, then, given that Pareto Indifference is satisfied, there exist numbers $a_{i}, i \in\{1, \ldots, n\}$, and $b$ such that for all elements $p$ from a set of lotteries $L$

$$
V(p)=\sum_{i=1}^{n} a_{i} V_{i}(p)+b .
$$

This means that the social utility of any $p \in L$ must be a weighted linear combination of the individual utilities. The theorem does not say that the weights $a_{i}$ have to be positive or at least nonnegative. Nor does it say that the vector of coefficients $\left(a_{1}, \ldots, a_{n} ; b\right)$ is unique. Furthermore, this mathematical representation theorem does not assume the possibility of interpersonal utility comparisons. Harsanyi (1978, p. 227) says that if such comparisons are ruled out, then the coefficients $a_{i}$ will have to be based completely on the evaluating person's "personal - and more or less arbitrary value judgments". The evaluator is not necessarily a member of the society that he is examining. Harsanyi (1978, p. 226) mentions judges and other public officials who will be "guided in their official capacities by some notions of public interest and of impartial justice". The evaluating person's moral preferences have to satisfy certain Bayesian rationality postulates so that "his moral value judgments will be such as if he tried to maximize a special utility function expressing these moral preferences" (p. 226). This utility function will be the evaluator's social welfare function.

The mathematical representation theorem does not say that the vector of coefficients $\left(a_{1}, \ldots, a_{n}\right)$ is positive. It can be rendered strictly positive by replacing Pareto Indifference by Strong Pareto. The vector of coefficients $\left(a_{1}, \ldots, a_{n} ; b\right)$ becomes unique by introducing a further requirement that Harsanyi did not make explicitly. This is the axiom of Independent Prospects which says that for each individual one can find a pair of prospects over which that person is not indifferent and over which every other individual is indifferent.

The second model - often referred to as the "impartial observer theorem" - was discussed by Harsanyi in a number of contributions (Harsanyi 1953, 1955, 1977, 1978). The basic idea is already to be found in Vickrey (1945). This model presupposes the possibility of interpersonal comparisons of utility. This is done in the way that an impartial observer who is sympathetic to the interests of each member of society makes moral value judgments for this society. More explicitly, the observer is to imagine himself being person $i, i \in\{1, \ldots, n\}$, under social alternatives $x, y$, etc. In making 
this sympathetic identification with individual $i$, the observer not only considers himself with $i$ 's objective circumstances under $x, y, \ldots$, but also is supposed to imagine himself with $i$ 's subjective characteristics, in particular with $i$ 's preference ordering. This comes close to the formulation that Smith was using to which we referred in the introduction. In order to be impartial, the observer has to enter a thought experiment in which he is imagining that he has an equal chance of being any person in society, complete with that person's objective and subjective circumstances. In this way, an equal consideration is given to each person's interests. In ranking the lotteries in $L$, the impartial observer, person $j$ - but it can be any $j \in\{1, \ldots, n\}$, calculates the average expected utility of each lottery so that for all $p \in L$, one obtains the formula of the arithmetic mean:

$$
V_{j}(p)=\frac{1}{n} \sum_{i=1}^{n} V_{i}(p) .
$$

The expression on the right hand side of this formula is person $j$ 's expected utility.

In his purely verbal 1953 paper, Harsanyi explicitly relates evaluations in terms of social welfare to the theory of choice involving risk. Specifically Harsanyi says that a person's value judgment on the distribution of income under complete ignorance of what this person's own relative position were within society would be a case of "impersonality to the highest degree" and "a clear instance of a "choice involving risk' "(pp. 434-35).

Several authors have drawn attention to conceptual difficulties with Harsanyi's two models (see e.g. Weymark (1991) and Mongin (2001)). Some have even claimed that the two models collapse into one. Harsanyi distinguished between them and took some care to point out, as mentioned above, that the first model does not presuppose that individual utilities be comparable across persons whereas the second model would be meaningless without such a requirement. Also, the second model allows one to maximize the arithmetic mean of individual utilities whereas the first only proposes maximizing the sum. Without wishing to downplay the conceptual problems with Harsanyi's models it is legitimate to say that they represent an important strand within modern utilitarianism.

The present paper is not intended to focus on conceptual issues within Harsanyi's utilitarian ethics. The purpose of this paper is to go into quite a different direction. We saw above that a social situation, a certain distribution of incomes, let us say, may either be evaluated by a "detached" person (e.g. a public official). Or it may be viewed through the eyes of a person who knows that he or she is occupying one of the positions in society but does not know which one, taking up an impartial and impersonal attitude though, as we have outlined above. Our focus of interest is whether the two sets of social situations are viewed as the same by the two types of observer. This point becomes even more interesting in the light of that position which considers the two models as basically being one model.

In what follows we set out, according to the structure of the two models, situations where certain vectors of income are to be evaluated, income vectors that arise from two different policies that we shall describe in the next section. We invite respondents 
to express their views on these income distribution vectors embedded in either the context of the first or the second model. More concretely, we ask our respondents to evaluate income distribution vectors under two policies $A$ and $B$ and state which policy, according to their view, leads to a better situation for the persons involved. This question has not been investigated in the present context where the perspective is on the position of the observer. The discussion about the Harsanyi models often revolved around the issues of linearity and interpersonal comparability. But here the question is whether the evaluations would differ with the status of the observer. ${ }^{1}$

\section{The situations to be evaluated}

The situations presented to our respondents are based on Amiel and Cowell (1998, 1999) and were originally used in a larger investigation concerning inequality and risk evaluations. For our current purposes, they were slightly rephrased in order to be as close as possible to Harsanyi who considers welfare evaluations in terms of utilitarian ethics.

The background for the questionnaires is a mythical country Alfaland that consists of five different regions. These regions are identical with respect to all aspects except for the incomes of their inhabitants. Within each region, there are no income differences among the inhabitants. It is assumed that two economic policies $A$ and $B$ are under consideration and that one of these is to be implemented next year. It is known that the only effect of either policy will be on the income in each region. However, the effect on the income in each region will depend on the economic situation then prevailing in Alfaland: it is supposed that there are six different states in which Alfaland may find itself in the coming year.

The Appendix shows the income distribution vectors under policies $A$ and $B$ for the six different situations in which Alfaland may find itself. In each situation policies $A$ and $B$ differ in the same way: a switch from policy $A$ to policy $B$ would represent a simple notional income transfer from a richer to a poorer region. ${ }^{2}$ The notional transfer affects different regions as one goes from situation 1 to situation 6 .

There are two versions of our questionnaire experiments. In the first we ask respondents to put themselves in the shoes of an outside observer who is asked to evaluate policies $A$ and $B$. In the second, they are asked to imagine that they themselves are assigned to one of the regions of Alfaland, with equal probability of finding themselves in one of the five regions.

In order to solve the evaluation problem, the two Harsanyi approaches would want the outside observer (the public official) and the involved observer to get as much utility information as possible from the different regions and then to maximize the respective sum of utilities. Our respondents, mostly undergraduates, could not be expected do

\footnotetext{
${ }^{1}$ For a theoretical perspective on this issue, see, among others, Mongin (2001).

${ }^{2}$ It is a notional transfer because only one of the two policies is actually implemented: we do not have policy $A$ followed by policy $B$, for example.
} 
this: most had not yet attended a class in welfare economics when they participated in the questionnaire experiment. In both versions they were asked to state which policy would, in their own opinion, lead to a better situation, so they had to form their own ideas of what "a better situation" for Alfaland would mean. Whether our respondents were assuming strictly concave utility functions for each region or even an identical utility function for all regions, we do not know.

In Harsanyi's models a positive or negative net effect on overall utilitarian welfare would depend on the properties of the individual utility functions. In his second model, which is much simpler since there is a common weight of $1 / n$ attached to the utility functions of all $n$ agents, a case of "relatively similar" strictly concave utility functions for all persons in society would, "with high probability", lead to the assertion that under policy $B$, aggregate welfare is higher than under policy $A .^{3}$

As noted earlier Harsanyi himself viewed his second model as a clear case of a "choice involving risk" (1953, p. 435), with the consequence that "the cardinal utility 'maximized' in value judgments concerning social welfare and the cardinal utility maximized in choices involving risk may be regarded as being fundamentally based upon the same principle" (p. 435). Harsanyi explained when a value judgment on the distribution of income would show impersonality to the highest degree. "This would be the case if the evaluating person had exactly the same chance of obtaining the first position (corresponding to the highest income) or the second or the third, etc., up to the last position (corresponding to the lowest income) available within that scheme" (p. 435). The phrasing in the second version of our questionnaire comes very close to this formulation.

\section{Results}

The six different situations were presented to samples of student respondents in a series of experimental sessions during 2003. ${ }^{4}$ All were first-year or second-year students of economics or business administration and came from the UK (LSE), Germany (Osnabrück) and Israel (Ruppin). In each case the respondents completed the exercise during class or lecture time and were randomly assigned an H1-type or H2-type questionnaire. Here H1 stands for the Harsanyi model with an outside observer, H2 represents the model where the observer himself is a member of the society to be evaluated,with probability $1 / n$ for each of the possible positions.

We start with the overall figures comprising results from all three countries. In Table 1 the six possible situations for Alfaland are labelled $Q_{1}$ to $Q_{6}$. For each individual situation, we state the percentage of answers that find that policy $B$ leads to a better

\footnotetext{
${ }^{3}$ This position is also consistent with approaches based on Dalton (1920).

${ }^{4}$ The empirical findings that are presented here form part of a broader investigation that looked at a larger class of approaches to distributional analysis. For the questionnaire experiment reported in Tables 1-4 the respondents were not offered monetary incentives to participate; but see the comments on Table 6 below.
} 


\begin{tabular}{|c|c|c|c|c|c|c|c|}
\hline & \multicolumn{7}{|c|}{ percentage choosing policy $\mathrm{B}$} \\
\hline & $N$ & $Q_{1}$ & $Q_{2}$ & $Q_{3}$ & $Q_{4}$ & $Q_{5}$ & $Q_{6}$ \\
\hline & & males & & & & & \\
\hline H1 & 76 & 63.2 & 81.6 & 72.4 & 61.8 & 85.5 & 61.8 \\
\hline $\mathrm{H} 2$ & 82 & 51.2 & 74.4 & 70.7 & 64.6 & 81.7 & 56.1 \\
\hline & & femal & & & & & \\
\hline H1 & 62 & 54.8 & 79.0 & 72.6 & 59.7 & 74.2 & 51.6 \\
\hline $\mathrm{H} 2$ & 64 & 60.9 & 84.4 & 59.4 & 45.3 & 70.3 & 50.0 \\
\hline & & all & & & & & \\
\hline H1 & 141 & 58.9 & 80.9 & 72.3 & 61.0 & 80.9 & 56.0 \\
\hline $\mathrm{H} 2$ & 149 & 55.0 & 78.5 & 65.8 & 57.0 & 76.5 & 53.7 \\
\hline
\end{tabular}

Table 1: Responses from all countries

situation in Alfaland than policy $A$, for all respondents and for males and for females separately. ${ }^{5}$ Coming back to a point made in section 3, such an assertion would definitely hold under a utilitarian viewpoint if the individuals in all regions had the same strictly concave utility function.

Although from previous studies there is evidence of rejection of the principle of transfers in the context of both inequality and of social welfare (Amiel and Cowell 1999) it was not clear a priori what response should be expected when comparing the two variants of the Harsanyi model. However, it is clear from the combined sample (Table 1) that there is a well-defined pattern: the proportions of $B$-responses in the outside-observer model vector dominate those in the model with involvement. The pattern is slightly less clear-cut when broken down by males and females. ${ }^{6}$ However, it is possible that there may be systematic differences between the groups of respondents in each of the locations where we conducted the experiment. So we examine each of the country subsamples.

For the UK subsample, there is again vector dominance of $\mathrm{H} 1$ responses over $\mathrm{H} 2$ (last two rows of Table 2). This vector dominance, which also holds for the female students, does not hold for males. ${ }^{7}$ For Germany, the results are similar (Table 3).

\footnotetext{
${ }^{5}$ The male-female breakdown is reported here because previous studies have shown a significant gender difference in responses to questionnaire-experiments - see for example Amiel and Cowell (2002). In the present study the number of males and females do not sum to the number of total observation: some respondents in the UK and Israel did not report their sex.

${ }^{6} \mathrm{~A}$ small-sample paired $t$ test for differences shows that the proportion of $B$-responses is significantly higher (at the 1\% level) in $\mathrm{H} 1$ compared with $\mathrm{H} 2$. Considering males alone, there is a dominance of $\mathrm{H} 1$ over $\mathrm{H} 2$ (significant at the $5 \%$ level) in five of the six questions; clearly question 4 is the exception. For the female subsample the proportion of $B$-responses is higher in $\mathrm{H} 1$ for only four out of six questions, and the results are not significant.

${ }^{7}$ The paired $t$ test for differences is highly significant for males and females combined (significance level below 1\%). For females alone $\mathrm{H} 1$ dominates at a $5 \%$ significance level. For males the proportion of $B$-responses for $\mathrm{H} 1$ is greater than or equal to those for $\mathrm{H} 1$ in all but one case but the differences are not significant.
} 
For the whole sample, there is vector dominance of $\mathrm{H} 1$ over $\mathrm{H} 2$ (at the $2 \%$ significance level). This time, the male percentages show a vector dominance of $\mathrm{H} 1$ over $\mathrm{H} 2$ (also at the $2 \%$ level); for the female responses, nothing like this happens. In three out of the six questions, the $\mathrm{H} 1$ percentages are higher, in the other three questions, the opposite is the case. This evidence suggests that there is clearly a greater propensity to conform to standard norms of distributional rankings if the issue is posed in terms of the Harsanyi outside-observer model rather than in terms of involvement.

\begin{tabular}{llllllll}
\hline \hline & \multicolumn{8}{c}{ percentage choosing policy B } \\
& $N$ & $Q_{1}$ & $Q_{2}$ & $Q_{3}$ & $Q_{4}$ & $Q_{5}$ & $Q_{6}$ \\
\hline \multirow{3}{*}{ H1 } & 24 & 62.5 & 79.2 & 70.8 & 66.7 & 79.2 & 62.5 \\
$\mathrm{H} 2$ & 30 & 56.7 & 66.7 & 73.3 & 66.7 & 73.3 & 60.0 \\
\cline { 3 - 8 } & & females \\
$\mathrm{H} 1$ & 18 & 72.2 & 88.9 & 83.3 & 83.3 & 83.3 & 72.2 \\
$\mathrm{H} 2$ & 13 & 53.8 & 69.2 & 46.2 & 38.5 & 46.2 & 38.5 \\
\cline { 3 - 8 } & & all & & & & \\
$\mathrm{H} 1$ & 43 & 65.1 & 83.7 & 76.7 & 74.4 & 81.4 & 65.1 \\
$\mathrm{H} 2$ & 44 & 54.5 & 68.2 & 65.9 & 59.1 & 65.9 & 54.5 \\
\hline
\end{tabular}

Table 2: Responses from UK subsample

\begin{tabular}{|c|c|c|c|c|c|c|c|}
\hline & \multicolumn{7}{|c|}{ percentage choosing policy B } \\
\hline & $N$ & $Q_{1}$ & $Q_{2}$ & $Q_{3}$ & $Q_{4}$ & $Q_{5}$ & $Q_{6}$ \\
\hline & & males & & & & & \\
\hline H1 & 31 & 74.2 & 80.6 & 80.6 & 64.5 & 93.5 & 74.2 \\
\hline $\mathrm{H} 2$ & 28 & 46.4 & 67.9 & 57.1 & 53.6 & 85.7 & 39.3 \\
\hline & & femal & & & & & \\
\hline H1 & 17 & 47.1 & 70.6 & 70.6 & 58.8 & 76.5 & 35.3 \\
\hline $\mathrm{H} 2$ & 24 & 62.5 & 79.2 & 45.8 & 37.5 & 75.0 & 50.0 \\
\hline & & al & & & & & \\
\hline H1 & 48 & 64. & 77. & 77.1 & 62.5 & 87.5 & 60 \\
\hline $\mathrm{H} 2$ & 52 & 53.8 & 73.1 & 51.9 & 46.2 & 80.8 & 44.2 \\
\hline
\end{tabular}

Table 3: Responses from Germany subsample

However, by contrast to the evidence of dominance of $\mathrm{H} 1$ over $\mathrm{H} 2$ for both the UK and Germany subsamples, the results for the Israel subsample are striking. In the case of Israel we again find significant differences in response patterns but in the opposite direction - see Table 4 . There is vector dominance with respect to $\mathrm{H} 2$ in all three cases, i.e. the complete sample and the two breakdowns for males and females. ${ }^{8}$

\footnotetext{
${ }^{8}$ Significant at the $1 \%$ level for males and females combined, at the $5 \%$ level for males or females taken separately.
} 


\begin{tabular}{llllllll}
\hline \hline \multicolumn{8}{c}{ percentage choosing policy B } \\
& $N$ & $Q_{1}$ & $Q_{2}$ & $Q_{3}$ & $Q_{4}$ & $Q_{5}$ & $Q_{6}$ \\
\hline \multirow{2}{*}{ H1 } & 21 & 47.6 & 85.7 & 61.9 & 52.4 & 81.0 & 42.9 \\
$\mathrm{H} 2$ & 24 & 50.0 & 91.7 & 83.3 & 75.0 & 87.5 & 70.8 \\
\cline { 3 - 8 } & & females \\
$\mathrm{H} 1$ & 27 & 48.1 & 77.8 & 66.7 & 44.4 & 66.7 & 48.1 \\
$\mathrm{H} 2$ & 27 & 63.0 & 96.3 & 77.8 & 55.6 & 77.8 & 55.6 \\
\cline { 3 - 8 } & & all & & & & \\
$\mathrm{H} 1$ & 50 & 48.0 & 82.0 & 64.0 & 48.0 & 74.0 & 44.0 \\
$\mathrm{H} 2$ & 53 & 56.6 & 92.5 & 79.2 & 66.0 & 81.1 & 62.3 \\
\hline
\end{tabular}

Table 4: Responses from Israel subsample

We appear to have evidence of cultural differences in the responses to the outsideobserver model and the involvement model. We also have a nice example of how aggregation can smooth out opposite answering behaviour: the (significant) results for the combined sample mask the (strongly significant) opposite results for the Israel subsample. But it leaves open the questions (a) whether it is some factor other than the apparent country effect which is driving the differences in response patterns and (b) whether the Israel results were idiosyncratic to that particular sample. To address these questions we took two further steps.

\begin{tabular}{rrrrrrrr}
\hline \hline & $Q_{1}$ & $Q_{2}$ & $Q_{3}$ & $Q_{4}$ & $Q_{5}$ & $Q_{6}$ & $A l l$ \\
\hline sex & $-0.2726^{\dagger}$ & -0.2402 & $-0.4317^{\ddagger}$ & $-0.4545^{*}$ & -0.2230 & $-0.3436^{\ddagger}$ & -0.2279 \\
age & -0.0144 & 0.0099 & 0.0099 & 0.0475 & 0.0421 & 0.0537 & 0.0010 \\
emp & -0.0872 & 0.2447 & -0.0671 & -0.2072 & 0.1746 & 0.0646 & 0.0684 \\
pol & 0.0280 & 0.0673 & -0.0211 & -0.1076 & 0.0218 & -0.0074 & -0.0987 \\
inc90 & -0.0836 & -0.0736 & -0.0232 & 0.0682 & 0.0735 & 0.0860 & 0.0434 \\
inc10 & 0.1351 & 0.1020 & 0.0123 & 0.0103 & $0.1737^{\dagger}$ & 0.1554 & 0.1064 \\
h1 & 0.1097 & -0.1159 & -0.0145 & 0.1458 & 0.1507 & 0.0399 & $0.3934^{\ddagger}$ \\
econ & 0.1134 & 0.1294 & 0.0329 & -0.1610 & 0.1534 & -0.2823 & -0.2262 \\
deutd & 0.1012 & 0.0382 & -0.2867 & $-0.3427^{\dagger}$ & $0.5162^{\ddagger}$ & -0.1162 & -0.0428 \\
israeld & 0.1594 & $0.5531^{\dagger}$ & 0.0634 & $-0.4741^{\dagger}$ & 0.0920 & -0.2854 & -0.0506 \\
const & -0.0372 & -0.0241 & 0.7077 & -0.0648 & -1.7472 & -1.6214 & -1.0621 \\
\hline
\end{tabular}

Table 5: Probit regression results

First we ran a simple probit regression to examine the role of personal characteristics 


\begin{tabular}{|c|c|c|c|c|c|c|c|}
\hline & \multicolumn{7}{|c|}{ percentage choosing policy $\mathrm{B}$} \\
\hline & $N$ & $Q_{1}$ & $Q_{2}$ & $Q_{3}$ & $Q_{4}$ & $Q_{5}$ & $Q_{6}$ \\
\hline & & male & & & & & \\
\hline H1 & 21 & 52.4 & 85.7 & 76.2 & 71.4 & 76.2 & 71.4 \\
\hline H2 & 26 & 57.7 & 80.8 & 80.8 & 88.5 & 69.2 & 69.2 \\
\hline & & fema & & & & & \\
\hline H1 & 29 & 58.6 & 75.9 & 69.0 & 65.5 & 62.1 & 62.1 \\
\hline $\mathrm{H} 2$ & 21 & $\begin{array}{l}61.9 \\
\text { all }\end{array}$ & 90.5 & 71.4 & 61.9 & 90.5 & 61.9 \\
\hline $\mathrm{H}$ & 5 & 54.9 & 80.4 & 70 & 68.6 & 68.6 & 64.7 \\
\hline $\mathrm{H} 2$ & 50 & 62.0 & 86.0 & 78.0 & 76.0 & 78.0 & 66.0 \\
\hline
\end{tabular}

Table 6: Responses from the second Israel sample

and other factors. ${ }^{9}$ The results in Table 5 show that whether the respondent is male or female and the country dummy are crucial in determining whether or not the response is "orthodox" in terms of the Harsanyi models. Almost without exception no other personal characteristic is significant.

As a second step we re-ran the Israel questionnaire experiment in 2005 with a fresh sample of respondents. On this occasion we used monetary incentives for participation. The comparison of the results for this second sample, given in Table 6, with Table 4 is again remarkable. Once again Israeli respondents demonstrate that - by contrast to those from the UK and Germany - there is a greater propensity to conform to standard norms if the issue is posed in terms of involvement rather than in terms of the Harsanyi

\footnotetext{
${ }^{9}$ The model is

$$
\operatorname{Pr}(\text { response pattern })=\beta_{0}+\beta_{1} x_{1}+\beta_{2} x_{2}+\ldots+\beta_{k} x_{k}
$$
}

where $x_{1}, \ldots, x_{k}$ are $k$ separate characteristics as follows:

- sex: male 0 , female 1

- age: in years

- pol: political views (on $1, \ldots, 7$ scale)

- inc90: income background (on $1, \ldots, 7$ scale)

- inc10: income prospects (on $1, \ldots, 7$ scale)

- h1: 1 if H1, 0 otherwise

- econ: 1 if special subject is economics

- deutd: 1 if Germany subsample

- israeld: 1 if Israel subsample

For further details on personal characteristics see the questionnaires in the appendix. The response pattern in the columns of Table 5 are "B response in individual question $i$ " (for $i=1, \ldots, 6$ ) and "B response in all questions $1, \ldots, 6$ simultaneously". 
outside-observer model. ${ }^{10}$

\section{Discussion}

A person who asserts that policy $B$ leads to a better situation for Alfaland than policy $A$ must be convinced that an income transfer from a richer region to a poorer region is welfare-increasing for the country. As we have noted, if the utility functions of all persons who are representative of each of the five regions are identical and strictly concave, the welfare-improving effect is unquestionable, independently of where the transfer occurs. However, even if the utility functions for all representative persons in each regions are strictly concave, the outcome is no longer so clear when the curvatures of the utility functions vary. In a utilitarian calculus, marginal utility losses have to be compared with marginal utility gains with the consequence that the net effect can be of any sign.

Our results now show that, for the combined sample of respondents, a welfareimproving effect of a transfer from rich to poor is more frequently acknowledged from the position of an outside observer than from the point of view of an observer who tries to be impartial but knows that he or she is involved. This statement is supported by the overall results from Germany and the UK whereas the opposite is the case for Israel.

The reasons for the difference between the UK and Germany on one side and Israel on the other could lie in demographic factors such as the historical or political background or some other experiences. The set of demographic questions (see the Appendix) that we had asked our respondents to answer does not seem to be able to explain this difference. So there must be other factors, possibly subsumable under the heading "cultural dimension".

That respondents from the UK and Germany acknowledge a transfer from rich to poor as welfare-increasing ("leading to a better situation in Alfaland") more frequently from the position of a detached observer than from the status of an impartial but involved evaluator could mean the following. From an outside or detached point of view where self-interest is not an issue and therefore, personal risks are not involved, they find the argument that a transfer from rich to poor is welfare-increasing more convincing than if they were personally affected, with a probability of $1 / n$ though. It is possible that whenever they feel directly involved, they would need more of a transfer from rich to poor in order to regard such a policy as welfare-improving or "better". If this inference is correct, it may have something to do with their personal attitude towards risk. By contrast, in a risky situation, Israeli respondents appreciate a transfer from rich to poor more than they do from the position of an outside observer. Recall that Harsanyi himself characterized the case of an impartial but involved observer as a clear instance of a choice involving risk. For the Israeli respondents, it could be the case that

\footnotetext{
${ }^{10}$ The fact that we obtain the same pattern of results in the two Israel samples, with and without payment for participation is consistent with Rubinstein's (1999) observations.
} 
from an outside or somewhat detached position, their demands for a welfare-improving transfer would have to be substantially higher. We say "substantially higher" because of the clear vector dominance that we have found. It is possible that they interpreted "better" as more egalitarian.

As we have seen, the two types of Harsanyi model - with or without involvement of the observer - elicit sharply different response patterns. It is evident that there are clear differences in these response patterns depending on the gender of the respondent and on their country of origin. The possible impact of cultural background on the attitude to fundamental distributional norms is an issue that deserves further exploration.

\section{References}

Amiel, Y. and Cowell, F. A. (1998). Distributional orderings and the transfer principle: a re-examination. Research on Economic Inequality 8, 195-215.

Amiel, Y. and Cowell, F. A. (1999). Thinking about Inequality. Cambridge: Cambridge University Press.

Amiel, Y. and Cowell, F. A. (2002). Attitudes towards risk and inequality: A questionnaireexperimental approach. In F. Andersson and H. J. Holm (Eds.), Experimental Economics: Financial Markets, Auctions, and Decision Making, Chapter 9, pp. 85-115. Deventer: Kluwer.

Amiel, Y., Cowell, F. A. and Gaertner, W. (2006). Distributional Orderings: An Approach with Seven Flavours. Manuscript. STICERD, London School of Economics.

Dalton, H. (1920). Measurement of the inequality of incomes. The Economic Journal 30, 348-361.

Harsanyi, J. C. (1953). Cardinal utility in welfare economics and in the theory of risk-taking. Journal of Political Economy 61, 434-435.

Harsanyi, J. C. (1955). Cardinal welfare, individualistic ethics and interpersonal comparisons of utility. Journal of Political Economy 63, 309-321.

Harsanyi, J. C. (1977). Rational Behavior and Bargaining Equilibrium in Games and Social Situations. Cambridge: Cambridge University Press.

Harsanyi, J. C. (1978). Bayesian decision theory and utilitarian ethics. American Economic Review 68, 223-228.

Herne, K. and Suojanen, M. (2004). The role of information in choices over income distributions. Journal of Conflict Resolution 48, 173-193. 
Mongin, P. (2001). The impartial observer theorem of social ethics. Economics and Philosophy 71, 147-179.

Rawls, J. (1971). A Theory of Justice. Cambridge, Ma.: Harvard University Press.

Rubinstein, A. (1999). Experience from a course in game theory: pre- and post-class problem sets as a didactic device. Games and Economic Behavior 28, 155-170.

Smith, A. (1759, [1976]). The Theory of Moral Sentiments. A. Millar, in the Strand, London. Republished and edited by D.D. Raphael and A.L. Macfie. Oxford: Clarendon Press.

Vickrey, W. (1945). Measuring marginal utility by reaction to risk. Econometrica 13, 319-333.

Weymark, J. (1991). A reconsideration of the Harsanyi-Sen debate on utilitarianism. In J. Elster and J. E. Roemer (Eds.), Interpersonal Comparisons of Well-Being. Cambridge: Cambridge University Press.

\section{A The questionnaires}

On the following pages are the two questionnaires (H1 and H2) that were distributed randomly within each group of respondents. 


\section{INCOME DISTRIBUTION QUESTIONNAIRE}

This questionnaire concerns people's attitude to income distribution. We would be interested in your view, based on hypothetical situations. Because it is about attitudes there are no "right" answers. Some of the possible answers correspond to assumptions consciously made by economists: but these assumptions may not be good ones. Your responses will help to shed some light on this, and we would like to thank you for your participation. The questionnaire is anonymous.

Alfaland consists of five regions that are identical in every respect other than the incomes of their inhabitants. Everyone within a given region receives the same income, but personal incomes differ from region to region.

Two economic policy proposals $\mathrm{A}$ and $\mathrm{B}$ are being considered for implementation in Alfaland next year. It is known that - apart from their impact on personal incomes the two policies would have the same effect on the population. The impact upon the regions' incomes would depend upon the particular state of the Alfaland economy at the time the policy (A or B) is to be introduced.

In each of questions (1) to (6) two alternative lists of incomes A and B (in Alfaland local currency) are given. Each of these pairs represents the outcomes of the A-policy and the B-policy on the five regions in each of six different situations in which Alfaland might find itself next year. Imagine that you are invited to be an outside observer of Alfaland. In each case please state which policy you consider would result in a better situation in Alfaland by circling A or B. If you consider that the two policies will result in an equivalent situation then circle both $\mathrm{A}$ and $\mathrm{B}$.
1) $\mathrm{A}=(2,5,9,20,30)$
$\mathrm{B}=(2,6,8,20,30)$
2) $\mathrm{A}=(2,5,9,20,30)$
$\mathrm{B}=(3,5,9,20,29)$
3) $\mathrm{A}=(2,5,9,20,30)$
$\mathrm{B}=(2,6,9,20,29)$
4) $\mathrm{A}=(2,5,9,20,30)$
$\mathrm{B}=(2,10,9,15,30)$
5) $\mathrm{A}=(1010,10,10,30)$
$\mathrm{B}=(10,10,10,20,20)$
6) $\mathrm{A}=(2,5,9,20,30)$
$\mathrm{B}=(2,6,9,19,30)$ 
Finally, we would be grateful for some information about yourself:

- Are you male or female? Please circle your answer.

- What is your age?

- What is your special subject of study?

- Were you employed before university? Please circle your answer.

- How would you rate your political views?

"extreme

"extreme Please put a $\times$ on this scale.

- How would you rate your family's income 10 years ago? Please put a $\times$ on this scale. poor"

- How would you rate your own income prospects 10 years from now? Please put a $\times$ on this scale.

$\begin{array}{cc}\text { "very } & \text { "very } \\ \text { poor" } & \text { rich" } \\ \square-\square-\square-\square-\square-\square-\square\end{array}$




\section{INCOME DISTRIBUTION QUESTIONNAIRE}

This questionnaire concerns people's attitude to income distribution. We would be interested in your view, based on hypothetical situations. Because it is about attitudes there are no "right" answers. Some of the possible answers correspond to assumptions consciously made by economists: but these assumptions may not be good ones. Your responses will help to shed some light on this, and we would like to thank you for your participation. The questionnaire is anonymous.

Alfaland consists of five regions that are identical in every respect other than the incomes of their inhabitants. Everyone within a given region receives the same income, but personal incomes differ from region to region.

Two economic policy proposals $\mathrm{A}$ and $\mathrm{B}$ are being considered for implementation in Alfaland next year. It is known that - apart from their impact on personal incomes the two policies would have the same effect on the population. The impact upon the regions' incomes would depend upon the particular state of the Alfaland economy at the time the policy (A or B) is to be introduced.

In each of questions (1) to (6) two alternative lists of incomes A and B (in Alfaland local currency) are given. Each of these pairs represents the outcomes of the A-policy and the B-policy on the five regions in each of six different situations in which Alfaland might find itself next year. Imagine that you have been assigned to one of the regions in Alfaland with an equal chance of being in anyone of the five regions. In each case please state which policy you consider would result in a better situation in Alfaland by circling $\mathrm{A}$ or $\mathrm{B}$. If you consider that the two policies will result in an equivalent situation then circle both $\mathrm{A}$ and $\mathrm{B}$.
1) $\mathrm{A}=(2,5,9,20,30)$
$\mathrm{B}=(2,6,8,20,30)$
2) $\mathrm{A}=(2,5,9,20,30)$
$\mathrm{B}=(3,5,9,20,29)$
3) $\mathrm{A}=(2,5,9,20,30)$
$\mathrm{B}=(2,6,9,20,29)$
4) $\mathrm{A}=(2,5,9,20,30)$
$\mathrm{B}=(2,10,9,15,30)$
5) $\mathrm{A}=(1010,10,10,30)$
$\mathrm{B}=(10,10,10,20,20)$
6) $\mathrm{A}=(2,5,9,20,30)$
$\mathrm{B}=(2,6,9,19,30)$ 
Finally, we would be grateful for some information about yourself:

- Are you male or female? Please circle your answer.

- What is your age?

- What is your special subject of study?

- Were you employed before university? Please circle your answer.

- How would you rate your political views?

"extreme

"extreme Please put a $\times$ on this scale.

- How would you rate your family's income 10 years ago? Please put a $\times$ on this scale. poor"

- How would you rate your own income prospects 10 years from now? Please put a $\times$ on this scale.

$\begin{array}{cc}\text { "very } & \text { "very } \\ \text { poor" } & \text { rich" } \\ \square-\square-\square-\square-\square-\square-\square\end{array}$

